\title{
CONTROL OF NEMATODES ATTACKING SUGARCANE
}

The Department of Entomology (Section of Nematology) of the Agricultural Experiment Station, has been studying the most economical and efficient means of controlling the nematodes that attack the roots of sugarcane. Nematological studies in the sugarcane fields of Puerto Rico indicate that the most common and important plant-parasitic nematodes found are the following: Spiral nematodes, Helicotylenchus spp.; reniform nematodes, Rotylenchulus spp.; stylet nematodes, Tylenchorhynchus spp.; meadow nematodes, Pratylenchus spp.; ring nematodes, Criconemoides and Hemicriconemoides spp.; and root-knot nematodes, $M$ eloidogyne spp. Other nematodes also occurring in sugarcane but less common are: Hoplolaimus, Paratylenchus, Aphelenchoides, Criconema, Tylenchus, Ditylenchus, Trichodorus, Xiphinema, and Longidorus.

Presently the methods most commonly used for the control of these parasites are complicated and often difficult to use. A thorough preparation of the soil, favorable weather and moisture conditions, a waiting period between fumigation and planting, and so on, are some of the conditions normally to be met for successful control. But with emulsifiable soil fumigants such as Nemagon and Fumazone, the attainment of these conditions is less necessary.

A number of experimental tests were made at the south coast of the Island to determine the effect of Nemagon on the germination of sugarcane. It was found that an application of one-half gallon per acre of concentrated Nemagon incorporated into the irrigation water increased the germination of the sugarcane seed by 50 percent, and the overall plant height by an average of $10 \mathrm{~cm}$.

Now an experiment has been set up at the Isabela Substation to determine the nematocidal effectiveness of Nemagon and Fumazone and their final effect on the yield of sugar of variety PR. 1013. Both nematocides were applied in the irrigation water at the rates of $1 / 2$ gallon and 1 gallon of concentrate per acre, using a Jaeco Gravity-Flow Fumigating $\mathrm{Kit}^{1}$ (see fig. 1.). The treatments were replicated six times. Control plots received water only.

1 The kit was obtained from the Joaquin Agricultural \& Engineering Co. Inc., Box 150, Hanford, Calif. 
Statistical analysis of the nematode populations before and after fumigation indicated that all treatments were significantly better in reducing the

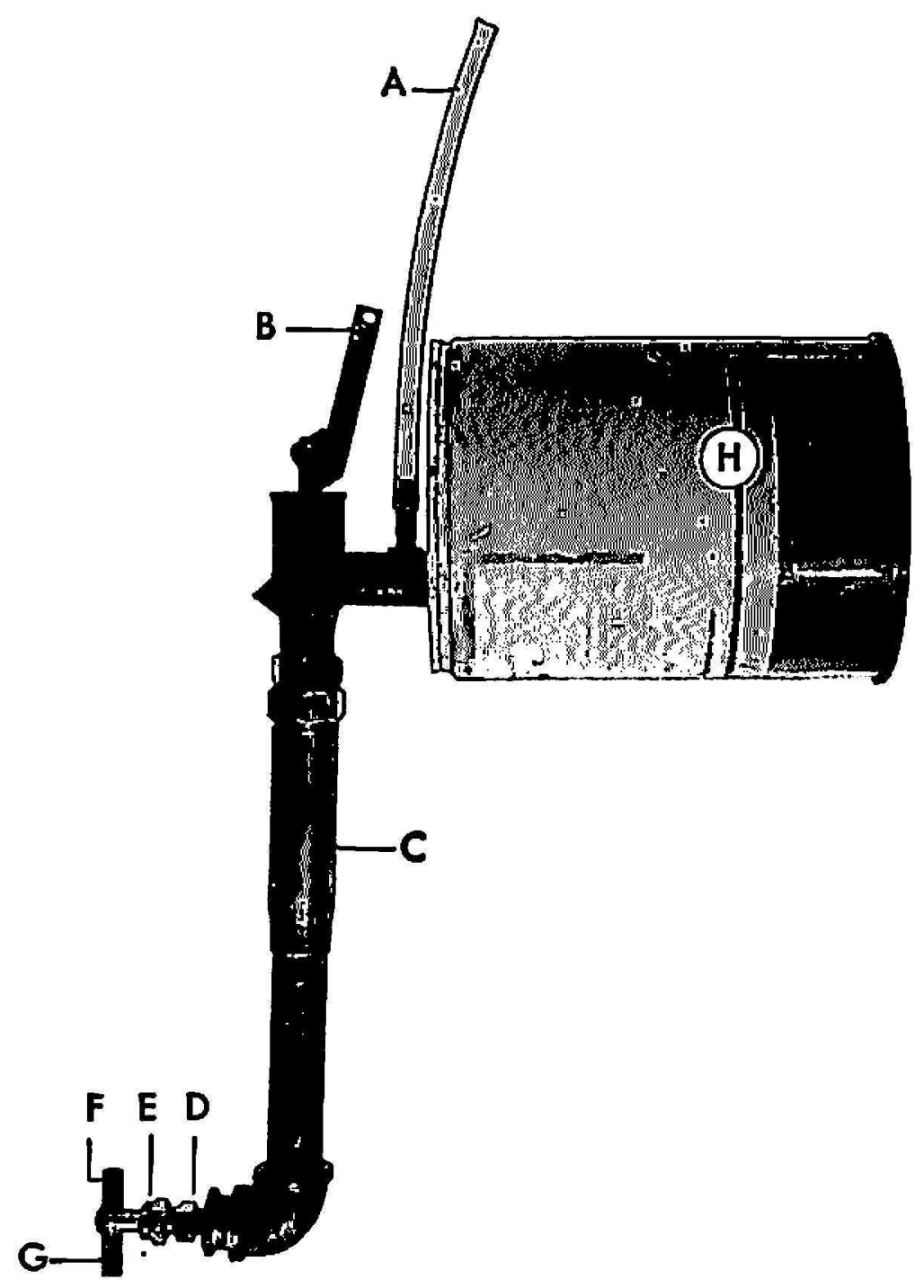

FIG. 1.-Jaeco gravity-flow fumigating kit: A, First air-intake tube; B, level of the valve that starts outflow; $C$, first impurity-retaining screen (inside tube); $D$, second impurity-retaining screen (inside tube); E, graduated orifice (inside tube); F, second air-intake tube; $\mathrm{G}$, outflow point; $\mathrm{H}$, chemical container.

number of nematodes when compared to the control. However, no significant differences were found between the nematocidal treatments.

Results of this experiment will be published when complete data are available. 